\title{
Education in Connectivity
}

Heather Greenhalgh-Spencer

\author{
Texas Tech University
}

Shortly before this fourth issue of Volume 76 of Philosophy of Education went to press, the Polar Vortex ${ }^{1}$ moved farther south than it has in a generation. It brough snow and ice and plummeting temperatures to where I live in Texas in a way that caught us all off guard. Texas (as Texas often does) has its own power grid. As the temperatures dropped, people turned up their heaters and used more power. This taxed the Texas power grid. All of the various components of the power grid had not been updated in decades. And, due to the lack of regulation, the grid and power-producing turbines, natural gas, and coal-fired plants had not received winterizing treatments or adequate repairs in decades. The grid came within seconds of completely collapsing. As it was - even without total collapse-rolling power outages were mandated in order to preserve what power there was for institutions like hospitals. More than half the state lost power for multiple days in their homes and businesses. People were without water because wells froze and the equipment used to clean the water at water plants was at a standstill because there was no electricity to run them. It was a nightmare!

It was also a lesson in connectivity. It was a lesson in the ways that the electrical grid is the backbone of so many things we take for granted. It was a lesson in the ways that all Texans are connected... and perhaps should have been connected to well-regulated power grids in other parts of the nation. Very few people had internet, and so it was a lesson in the connectivity that can be fostered online and that we often take for granted. Suddenly, people did not go out of their homes (the roads were not safe, COVID-19 was still in full swing, everything was shut down), and yet they also lost their way to connect with the outside world. No television. No internet. All of it takes electricity. You had phone access only if your battery had not died yet. It was a grim reminder of the value of being connected to other people: to other beliefs 
and ways of knowing, as well as to other locations within the world. Perhaps because this is still a recent event in my mind, I see the collection of writings in this issue through the lens of connectivity. Each grouping fosters connections in a way that amplifies what the other papers in the group have to say.

The first group of papers come from Leigh Patel and Lisa Weems. Dr. Patel gave the Kneller Lecture at PES 2020, and her talk is a meditation on that experience. Patel makes connections between and among various ways of knowing; while foregrounding the ways that identity and positionality foster a sense of who is safe, and when, and where; and the ways that interconnectedness can foster safety and act as an intervention into colonial violence. Weems extends and contextualizes Patel's argument by highlighting the ways we are connected not just to each other and to our histories (including violent histories of colonialism), but also to the earth and other materialities. Weems foregrounds the 'more than human' forces, objects, subjects, and locations that also make up nodes on our network and part of our sense of connectivity. Weems bridges between Patel's article and work by other scholars who focus on decolonializing practices. In this way, too, Weems's response models connectivity.

The next group of papers work around Sarah Stitzlein's new book Learning How to Hope. Stitzlein focuses on ways we can scaffold and reclaim democracy through various practices in schools. Her primary focus is on practices of Hope; and not just lower-case letter hope that stands in for grit or optimism, but an upper-case letter Hope (HOPE) that fires up real action toward sustaining democratic practices. Here, too, Stitzlein focuses on our connections to each other as a medium for practicing democracy and, in that practicing of democracy, reaffirming and supporting democracy in civil society. Gottlieb's article connects to Stitzlein's by picking up the concepts of 'habit' and 'publicness'. Gottlieb argues for a careful and nuanced understanding of the ways that the publicness of our connections shapes our practices (and habits) of democracy. Thompson, too, connects to Stitzlein's book by taking a contrarian view of the hope she aims to foment. Thompson is skeptical of the power of hope, and highlights the political reality that, for many, 
drives hope away. Furthermore, he argues that hope is a luxury, and not, in fact, needed for civic engagement or democracy. While Thompson and Stitzlein clearly disagree, their connections to each other's work make for complex and provocative reading. Joldersma, too, takes up Stitzlein's book by focusing on the various natures and versions of hope that exist. Joldersma contrasts religious notions of hope with the hope that is expressed in the writings of Cornel West and others, as well as the hope expressed by Thomas Paine and other revolutionaries. Joldersma extends the idea of a religious notion of hope as an animating force. It is this hope that propels labor and love; this hope seeds and feeds democratic practice. All of the authors in this group connect (through extension and even opposition) to each other's work in ways that show the value of connectivity for generating new thoughts and new ways of practicing being in the world.

The final group of articles reflects on the roles of whiteness in racism. Applebaum, Nikolaidis, Thompson, and Fraser-Burgess connect over important topics like: Racial Battle Fatigue; Willful Ignorance; Root Causes of Epistemic Injustice; Communication Across Difference; Wages of Whiteness; and Identity Formation. Each of the authors in this group connects with the others over claims about how to fight against racism, and how to support identity formation that does not require willful ignorance or turning away from the exploitation of others. Here, too, the relationships we build and the connections we make are spotlighted for their ability to spur action.

These articles are a final 'Amen' to the series of articles in Volume 76 that have spotlighted the concept of 'bridges' and 'bridge building'. These articles, in particular, showcase the importance of connecting, or aiming to connect, even of the connection comes in the form of disagreement. They have modeled the importance of continuing to reach out and over our differences.

1 “The Polar Vortex Explained”. National Geographic. Retrieved on February 23, 2021: https://www.nationalgeographic.com/environment/article/ polar-vortex 